\title{
PHYSICS IN AFRICA
}

$\mathrm{P}^{\mathrm{H}}$ ROBLEMS and opportunities facing physics departments in African universities were discussed at the Leverhulme Inter-Universities Conference held at Salisbury, Southern Rhodesia, during June 10-20. The delegates, drawn mainly from the region between the Sahara Desert and the Limpopo River (with two advisers from the United Kingdom) were of many nationalities-Indian, Norwegian, French and Belgian, as well as British, Nigerian and South African. The institutions which they represented included small and recent foundations (such as Roma, Basutoland, with 173 students) along with others of greater size and seniority.

Many African universities, having grown out of institutions established in Colonial days, retain close links with the mother countries. French influence is still strong at Dakar (Senegal) and Abidjan (Ivory Coast); the University of Lovanium, in Léopoldville, is run on characteristic ally Belgian lines. Several colleges in former British territories were originally in special relation with the University of London; only one (the University College of Rhodesia and Nyasaland) rotains this status, the others having all taken steps to secure autonomy. New foundations in Ghana, Nigeria, Tanganyika and elsewhere will, it is expected, grant their own degrees from the outset.

The universities of mid-Africa present a rich diversity of constitution, tradition and academic outlook, but they have many problems in common. The formation of new universities - now proceeding at a rate unequalled even in the United Kingdom-is part of the movement towards independence. It would be an over-simplification to regard the universities in developing countries merely as symbols of national pride, but it must be accepted that the advancement of learning in many African territories is closely linked with the contemporary political ferment.

The first problem discussed at the conference was the role of the universities in an emerging country. The definition offered recently by an African politician ("factories for graduates") expresses one view of the situation. The repatriation of Colonial administrators and experts of all kinds creates serious problems in newly independent countries, where facilities for higher education have often been very limited. It is, however, not certain that university expansion should have first priority in the effort to build up the local supply of professionally trained people. Several universities are short of students, particularly in science, because of deficiencies in the provision of secondary education for African children. Many universities follow the present English practice by requiring candidates for admission to have at least two advancedlevel passes in the General Certificate of Education. This is a higher standard than is now required in a number of advanced countries, including South Africa, India, Scotland and the United States. Its attainment in African conditions is extraordinarily difficult. In Southern Rhodesia, for example, 129,000 African children began their primary education in 1962 but fewer than 6,000 were enrolled in secondary schools and only 81 remained at school after taking the Ordinary-level examination for the General Certificate of Education. About half these students may eventually graduate and not all of them are likely to become teachers.

The Conference agreed that expansion of secondary education will be necessary before the universities can play their full part in the communities that they serve. Meanwhile, the universities are under pressure to organize (as some have already done) a preliminary year to bring students of limited academic attainment up to the standard required for entry to a degree course.

The shortage of African students is both the cause and the consequence of the shortage of teachers. Since few countries in the world have enough well-qualified teachers, it is becoming more difficult for African schools to recruit staff from abroad. An imaginative scheme sponsored by the United Nations, at a cost of more than $£ 300,000$, will attempt to deal with this situation by bringing several hundred recent graduates, from all over the English. speaking world, to Salisbury. They will study at the University College of Rhodesia and Nyasaland for the postgraduate certificate in education of the University of London and will then teach in various African countries.

The inter-dependence of school and university was discussed further when the conference passed to its second main topic, the teaching of physics to undergraduates. The African child, reared in a culture based on folk-lore and witcheraft (which the white man has disturbed without adequately replacing) does not take readily to the study of science. Having had no contact with modern technology, he finds difficulty in scientific and mechanical tasks which his contemporaries in Europe or North America would consider trivial (one delegate suggested the distribution of 'Meccano' in primary schools as a useful preparation for later scientific studies). The African teenager may even be suspicious of experimental science as an activity more akin to manual labour than to intellectual exercise.

Against this background it is unreasonable to plan for a large output of highly qualified honours graduatesparticularly since the abler students can often obtain scholarships to support their undergraduate studies in foreign universities. It is judged that a considerably increased supply of physicists at the level of the general honours or the pass degree would best serve the shortterm needs of most African countries.

Although the universities are not yet able to produce great numbers of physicists, there is much to be done in the teaching of physics as a subsidiary subject at undergraduate-level. Reference was also made to the physicist's role in the advancement of technical education. Training courses for technicians are not popular, even where the industries which need the products are already established. The educated African hopes to obtain a degree, which confers much improved status and earnings. Short of a degree, he will often prefer clerical employment to technical work, which is not yet esteemed as the foundation of a 'respectable' career.

The conduct of research was the third major theme of the conference. A physics department in Africa has, as elsewhere, three main tasks: $(a)$ the teaching of students; (b) the advancement of knowledge; $(c)$ the application of scientific ideas and methods to practical problems arising in industry, agriculture, defence and other public activities. An active research effort is, the Conference urged, essential for the fulfilment of all three of these responsibilities. The maintenance of such an effort is difficult. The most serious handicap reported by many delegates was the lack of research students. The output of honours graduates suited for further training is small, and most of them prefer to go abroad for their research experience. On the other hand, expatriate staff are not generally recruited below the lecturer-level. In these circumstances, many African universities are not able to offer the $\mathrm{Ph} . \mathrm{D}$. degree. It was agreed that a successful physics department must have some measure of continuity, through the postgraduate training and eventual absorption (as staff members) of its own students. Free movement of scientists is important, but every department should be able to recruit a proportion of its staff from among its own graduates.

Some of these problems will solve themselves as African universities grow in stature and resources. Meanwhile, the Conference recommended, two steps should be taken. First, the institution of an intermediate research degree, 
at the M.Sc. level, would be a useful measure towards the growth of participation by African students in the research programmes of physics departments. Secondly, the help of the Department of Scientific and Industrial Research and of other research-sponsoring organizations should be sought in the recruitment of research students from overseas.

In the absence of research students, much of the experimental work in a project has to be done by the lecturers, or by the small number of full-time research fellows. Progress is further retarded by the shortage of technicians. The supply of assistance at this level depends on the provision of secondary education (up to Ordinary-level) in mathematics and physics and also on the development of full-time or part-time technical education to the level of the Ordinary National Certificate or the City and Guilds final examination in appropriate subjects.

Educational facilities of this kind are essential to the development of a healthy industrial economy and are, therefore, of great importance in many African countries. Their provision will be a slow process, and physics departments will have to rely on expatriate technicians--who can do valuable service in the training of indigenous staff.

Physics departments in Africa are isolated in the geographical sense, but they also face the danger of intellectual isolation. Many active areas of modern physics are closed to them, through lack of funds for equipment and staff. Contacts with other physicists are also very limited. Chemists and biologists can be found in most countries, going about their normal work in industry, agriculture or
Government service. Physicists are needed mainly in industrialized communities; consequently teachers in African universities can seldom sharpen their wits by contact with practising physicists in the outside world. African universities in general make reasonable provision for overseas leave; the Conference emphasized the value of attendance at scientific conferences and of frequent discussion with visiting research workers.

Despite many obstacles and discouragements, a lively spirit of enquiry is evident in many physics departments. Good use is being made of the excellent local opportunities for research in geophysics (including seismic studies and palæomagnetism), meteorology, cosmic radiation and ionospheric investigation. The cost of this research is largely defrayed by European or American sources or by international organizations.

Physics departments in Africa face some of the difficulties which were known in English provincial universities forty years ago. Student numbers are small (one African university has 186 first-year students in history, but only 15 in physics), because physics is not yet seen to have any immediate relevance to the needs of the community. The teaching load is nevertheless heavy. Funds for equipment are meagre and research is a constant struggle. British physics advanced rapidly as a consequence of the Second World War; the political upheaval which is now transforming the African scene must, for its full consummation, be accompanied by an upsurge of science and technology. Physicists now working in African countries are fully alive to their responsibilities at this exciting time.
J. M. A. LENIHAN

\section{FREE RADICALS}

$\mathrm{T}$ THE sixth International Symposium on Free Radicals was held in the Department of Physical Chemistry in the University of Cambridge during July 2-5. The meeting had an extensive scientific programme; but pre-printing of the papers made it possible to avoid parallel sessions. The delegates were accommodated in Trinity Hall, Sidney Sussex and Downing Colleges, and the social functions, which included a reception in the Guildhall and a guest night dinner held in St. John's and Downing Colleges, provided plenty of opportunity for discussions. The three hundred delegates included Dr. W. A. Noyes, jun. (president of the International Union of Pure and Applied Chemistry), Academician V. N. Kondratiev, Prof. S. Claesson, Prof. P. A. Giguère, Dr. G. Herzberg, Academician W. Kemula, Dr. Bernard Lowis, Dr. F. O. Rice and Prof. G. Semerano.

The inaugural lecture was given by Prof. R. G. W. Norrish, who discussed the many ways in which kinetic spectroscopy and flash photolysis have contributed to the understanding of the properties of free radicals.

As with previous symposia, the emphasis of the plenary lectures and contributed papers was primarily on free radicals in the liquid and solid states, although $H$. Schüler and G. Arnold (Göttingen) discussed the dissociation of cyclohexane and $n$-butane into different radicals and diradicals by slow electrons in the positive column of a glow discharge. Electron bombardment in the gas phase was also used by R. Marx, S. Leach and M. Horani (Orsay, Paris) to produce free radicals from water. The radicals which could be condensed from an electric discharge through water vapour were also discussed by P. A. Giguère (Laval, Quebec). The closely related problem of using electron spin resonance to identify the radicals produced in the radiolysis of ice and hydrogen peroxide water systems at low temperatures was discussed in a plenary lecture by R. Livingston (Oak Ridge, Tennessee) and in papers by D. Schulte-Frohlinde and K. Eiben (Karlsruhe), I. Safarik, B. C. Green and J. W. T. Spinks (Saskatoon) and S. J. Wyard and R. C. Smith (Guy's
Hospital, London). The existence of hydrogen superoxide $\left(\mathrm{H}_{2} \mathrm{O}_{4}\right)$ is not unequivocally established in these systems, but there is clear evidence for the trapping of $\mathrm{OH}$ and $\mathrm{HO}_{2}$. The nature of the active species in the radiolysis of aqueous solutions was also discussed in a plenary lecture by J. Weiss (King's College, Newcastle upon Tyne).

Several papers were concerned with the identification and study of the electron spin resonance spectra of trapped radicals produced by irradiation of both organic and inorganic solids. It was significant that a high proportion of the work reported was carried out on single crystals. These papers were preceded by a plenary lecture on the interpretation of hyperfine coupling by $\mathrm{D}, \mathrm{H}$. Whiffen (National Physical Laboratory, Teddington), and the parent compounds studied included persulphates by P. W. Atkins, J. A. Brivati, A. Horsfield, M. C. R. Symons and P. A. Trevalion (Leicester); nitrates by J. Cunningham (Chicago) and R. M. Golding and M. Henchman (Cambridge); fluorinated organic compounds by J. K. Brown and D. S. Stiles (Birmingham); succinimide by N. M. Atherton (Sheffield); olefines and alkyl halides by P. B. Ayscough and H. E. Evans (Leeds); organic acids by R. J. Cook, J. R. Rowlands and D. H. Whiffen (National Physical Laboratory, Teddington); and acetylene by E. L. Cochran, V. A. Bowers and F. J. Adrian (Applied Physics Laboratory, Johns Hopkins).

Three contributions described the use of electron spin resonance to examine reactions of radicals produced by irradiating both hydrocarbon polymers (H. Fischer, K. H. Hellwege and P. Neudörfl (Darmstadt) and A. Charlesby, C. Graves, P. G. Garratt and P. M. Kopp (Royal Military College of Science, Shrivenham)) and polymethylsiloxane (H. Ormerod (Royal Military College of Science, Shrivenham)). Electron spin resonance was one of the many techniques mentioned by C. H. Bamford (Liverpool) in his plenary lecture on radical polymeriza. tion in the solid-state. The unusual reactivity and exceptional surface area of fluffs obtained by freeze- 